\title{
Data Analytical Approach for Regional Variation of Incidence Rates for Asthma and Other Chronic Obstructive Lung Diseases in Oman
}

Ronald Wesonga ( $\nabla$ wesonga@squ.edu.om )

Sultan Qaboos University https://orcid.org/0000-0003-4887-9088

Khidir Abdelbasit

Sultan Qaboos University

\section{Research}

Keywords: Machine learning, Asthma incidence, regional differences, Statistics

Posted Date: November 8th, 2021

DOI: https://doi.org/10.21203/rs.3.rs-1032316/v1

License: (c) (1) This work is licensed under a Creative Commons Attribution 4.0 International License.

Read Full License 


\section{Abstract \\ Background}

This study aimed to examine regional differences for asthma and other chronic obstructive lung diseases. Information pertaining influence of region on asthma is not well established.

\section{Method}

The study was based on data collected from annual reports produced by the Ministry of Health over a ten-year period beginning from 2010 to 2019 . Incidence rates per 10000 populations for the eleven regions in the Sultanate of Oman were analyzed using statistical tools including; analysis of variance and binary logistic regression model to determine the effect of region on asthma and other chronic obstructive lung diseases.

\section{Results}

The incident rates were found to be significantly different by region ( $F$-value $=27.07, p=0.00$ ). There was no significant variation by year (F-value $=1.05, p>0.407$ ). Overall over the ten-year period the incidence rates stagnated between 250 and 300 per 10000 of the population, but showed a reducing trend between 2016 and 2019. The logistic regression model shows that compared to the Muscat region, all the other regions had significant increased odd ratios.

\section{Conclusion}

There is a significant evidence of regional variation in the incidence of asthma and other chronic obstructive lung diseases. This implies probable characteristics in geographical regions that are associated with asthma and other chronic obstructive lung diseases' exacerbation. Five asthma-region classifications were identified from our analysis. Findings of this study may be used to guide decision making towards the management and control of asthma and chronic obstructive lung diseases.

\section{Advances To Knowledge}

- This study used official data to examine differences in asthma and other chronic obstructive lung diseases within the Sultanate of Oman.

- There was a statistically significant difference in asthma and other chronic obstructive lung diseases among regions (governorates).

\section{APPLICATION TO PATIENT CARE}


- Understanding regions with higher asthma incidence informs decisions about resource allocation, in which case the patients can receive quality and timely care.

\section{Introduction}

The incidence and etiology of asthma in the human populations is exacerbated by factors that may be classified as genetic and environmental. Studies have established a strong genetic and environmental linkage that interacts both in the induction and subsequent expression of the disease phenotypes 1,2 . In their recent study 3 , have established that among farm children, asthma is more determined by genetic polymorphisms, while in non-farm children, it is mainly environmental factor-driven. Multiple genes are involved and sometimes interact, but studies to identify the exact asthma-related gene are still being developed 4-7. On the other hand, the epithelium, which is in contact with the environment, and the underlying cells (fibroblasts and dendritic), indicate reactivation of the unit (epithelial mesenchymal trophic) that provides a source for asthma 8-10. Although, studies confirm the effect of environment on exacerbating asthma, not many studies have provided substantial data-centered evidence to support the hypotheses. In this study, we tested the effect of region to examine its effect on the variation in the incidence rates for asthma and other chronic obstructive lung diseases within Oman.

Asthma and other chronic obstructive lung diseases (ACOLD) within the Sultanate of Oman present a complicated scenario resulting into episodic exacerbations, caused by persistent and variable airway obstruction 11,12 . In the medical field, asthma has been described as difficult due to poorly controlled chronic symptoms, or resulting from patients with refractory asthma who remain difficult to control despite an extensive re-evaluation of diagnosis, management, and following an observational period of at least six months by an asthma specialist 13-16. Its known that approximately $5 \%$ of patients are not controlled even on high doses of inhaled corticosteroids 17, 18. The ACOLD are known to contribute to substantial healthcare, societal costs and general poor quality of life, mainly attributable to poor asthma control 19.

It is noteworthy that disease severity and poor response to treatment are mainly associated with genetic and environmental factors. A number of risk factors such as region, race, sex, body mass index (BMI), diabetes and lung function, have been investigated with differing outcomes 20,21 . Our study sought to examine ACOLD incidence, distribution and determine the effect of region on incidence rates.

\section{Methodology}

\section{Study Design}

This study was based on data collected from annual reports produced by the Ministry of Health, and archived on their website. Quantitative data on asthma and other chronic obstructive lung diseases' 
incidence data from eleven regions (governorates) for a ten-year period from 2010 to 2019 were analyzed.

\section{Data Analysis}

We evaluated two predictors, region and year to assess the incidence rates among the population. Data analysis was performed primarily to achieve the set specific objectives mentioned above. The incidence rates were measured as a rate per 10000 of the population for the period of study.

\section{Assessing regional differences using analysis of variance}

With region and year as factors, a two-way Analysis of variance (ANOVA) main effects model was fitted to assess the main effects of the two factors 22-25. We applied this approach to establish if there existed significant effects on incidence rates by region and year. Since we have only one observation per (region, year) category, we assume no region-year interaction to be able to assess the effects of year and region. Besides an assumption of interaction is hard to justify, since its existence implies overall regional variation in incidence rates are not meaningful unless they are examined year by year. Since the years in question have passed, a main effects model was fitted. Using the Duncan's multiple comparisons test, we identified the most significant differences. Duncan's test was used rather than least significant difference (LSD) to avoid inflating the overall probability of type I error to a level much higher than 0.05. As a followup, a one-way analysis of variance and a nonparametric test were also carried out.

\section{Determinants of asthma incidence rates}

Since incidence rates are proportions resulting from a binary classification of the population as diagnosed with Asthma or not, a binary logistics regression analysis is a more natural approach to study the effects of region and year on the odds of asthma. A binary logistic model with Muscat as a reference category was fitted. Regions are compared with Muscat because unlike other regions, Muscat is the capital of the country and the most metropolitan region. Year was included in the model to provide an estimate of the annual change in the odds of incidence of asthma and other chronic obstructive lung diseases.

\section{Estimation And Results}

We present the study findings beginning with the general distribution of asthma incidence by region and year, followed by analysis of variance (ANOVA) and the logistic regression model. The analyses were aimed at determining the effect of region on the incidence of asthma and its possible distribution over the regions.

\section{Incidence rates by region and year}

Figure 1 displays the incidence rates by year and region. It shows that the incidence rates were relatively stable over the ten-year study period for most of the regions except Dhofar and Al Wusta. Whereas incidence rates for Dhofar decreased, those for Al Wusta increased between the year 2010 and 2019. The 
rates for Musandam were consistently higher than other regions followed by those in South Ash Sharqiyah region. The figure provides no clear evidence of region-year interaction.

Table 1, gives the mean (standard deviation) for regions and years. The standards deviations show the erratic variability of incidence rates in Dhofar and Musandam. 
Table 1

Incidence rates for Asthma and other chronic obstructive lung disease by Region and Year

\begin{tabular}{|c|c|}
\hline Parameter & Incidence Rate Per 10000 population \\
\hline Region & Mean (SD) \\
\hline Musandam & $499.1(73.6)$ \\
\hline Al Wusta & $434.5(151.2)$ \\
\hline Dhofar & $394.6(176.6)$ \\
\hline South Ash Sharqiyah & $311.5(31.6)$ \\
\hline North Al Batinah & $220.9(27.0)$ \\
\hline South Al Batinah & $202.6(19.9)$ \\
\hline Ad Dhahirah & $200.5(37.5)$ \\
\hline Al Buraymi & $196.4(67.6)$ \\
\hline Ad Dakhliyah & $183.5(26.5)$ \\
\hline North Ash Sharqiyah & $158.2(27.6)$ \\
\hline Muscat & $75.1(14.2)$ \\
\hline \multicolumn{2}{|l|}{ Year } \\
\hline 2010 & 257.9(193.5) \\
\hline 2011 & 234.0(133.3) \\
\hline 2012 & $280.0(168.4)$ \\
\hline 2013 & 279.6(159.4) \\
\hline 2014 & 270.0(139.3) \\
\hline 2015 & $278.0(154.5)$ \\
\hline 2016 & 289.7(163.3) \\
\hline 2017 & 275.0(161.1) \\
\hline 2018 & 232.1(112.6) \\
\hline 2019 & $219.0(102.7)$ \\
\hline
\end{tabular}

\section{Analysis of variance of incidence rates of asthma and other chronic obstructive lung disease}


To test the hypothesis for existence of differences in asthma incidence among the eleven regions, and the ten years, we used analysis of variance (ANOVA) and the null hypotheses of no differences in mean incidence rates for regions or years were tested (see Table 2). There were highly significant differences in asthma incidence rates among regions $(F=27.072, p=0.001)$; however, these differences were not significant among the years $(F=1.051, p=0.407)$. Further our model shows that region and year explain about $75 \%$ of the variation in incidence rates $(R 2=0.757)$. Since there is no evidence of variation among years, a one-way ANOVA was fitted using regions only, resulting to the same conclusion of highly significant differences among regions $(F=26.948, p=0.001)$. Here, regions explain about $73 \%$ of the total variation in incidence rates ( $R 2=0.73$ ) indicating that yearly variations account for about $3 \%$ only of the total variability in incidence rates.

Table 2

Analysis of variance for Asthma and other chronic obstructive lung disease by region and year.

\begin{tabular}{|llllll|}
\hline Parameter & Degrees of freedom & Sum of Squares & Mean Square & Fvalue & Pvalue \\
\hline Region & 10 & 1711748 & 171175 & 27.072 & 0.000 \\
Year & 9 & 59785 & 6643 & 1.051 & 0.407 \\
Residuals & 90 & 569061 & 6323 & - & - \\
\hline
\end{tabular}

Multiple comparisons of the average incidence rates between regions using Duncan's multiple range test at the 0.05 alpha-level of significance was carried out. This comparison (from both one way and two way analysis of variance) gave the same result. Five groups were identified, where regions in different groups have significantly different incidence rates, while regions in the group are not significantly different. The groups arranged in order from lowest to highest incidence rate as follows:

1. The first group is made up of only the Muscat region with the lowest average rate of 75 per 10000 . This region hosts the capital city, it is urban, metropolitan, with plenty of government and private clinics and health care facilities.

2. The second group is made up of six geographical regions, that is North As Sharqiya, Ad Dakhliya, Al Buraimi, Ad Dhahira, South Al Batina and North Al Batina with average rates ranging from 158 to 220 per 10000. They are basically located in the central and interior area of Oman.

3. The third group is made up of only the South As Sharqia region with an average rate of 312 per 10000. This region is located on the East coast.

4. The forth group is made up of two regions, Dhofar and AI Wusta with average rates of 395 and 435 per 10000. These two are located in the Central and Southern parts of the country.

5. In the fifth group is the Musandam region with average rate of about 500 per 10000 . The Musandam region is located in the far north, separated from the mainland by the United Arab Emirates, it is a mountainous peninsula. 
Overall, the incidence rate in Muscat region was by far the lowest in the country, followed by those regions in the Central, then the South and the far North of Oman. There was evidence of lack of homogeneity of variance (Levene's test statistic $=4.867, \mathrm{p}=0.000$ ). Evidence of lack of homogeneity suggested performing analysis based on a nonparametric method and the Friedman's nonparametric test was used to test differences between regions. This led to the same conclusion (Friedman's Test Statistics $=37.843, p=0.000$ ).

\section{Determinants of asthma and other chronic obstructive lung disease incidence rates}

Binary logistic regression is more appropriate technique for examining the effects of a number of qualitative and quantitative explanatory variables on a binary response and hence for rates and proportions. It models the logarithm of the odds ratio as a linear function of the explanatory variables. Muscat was taken as the reference category for other regions and year was entered as a quantitative variable. Table 3 summarizes the results. The negative coefficient for year shows that overall incidence rate is decreasing over the years. The odds on incidence of asthma and other chronic obstructive lung disease decrease by about one percent per year. All the coefficients for regions are positive, confirming that they all have higher incidence rates than Muscat. The estimated odds of incidence for regions range from twice the odds for Muscat in North Sharqiya, to six fold as in Al Wusta and Musandam. We noted that the regions ordered from lowest to highest estimated odds of incidence is the same as the order of the observed raw incidence rates. 
Table 3

Binary logistic Regression analysis of Incidence rates.

\begin{tabular}{|c|c|c|c|c|c|c|c|c|}
\hline \multirow[t]{2}{*}{ Variable } & \multirow[t]{2}{*}{$\begin{array}{l}\text { Coefficient } \\
(\beta)\end{array}$} & \multirow[t]{2}{*}{ SE } & \multirow[t]{2}{*}{$\begin{array}{l}\mathrm{P}- \\
\text { value }\end{array}$} & \multicolumn{2}{|c|}{$95 \% \mathrm{Cl}$ for $\beta$} & \multirow[t]{2}{*}{$\begin{array}{l}\text { Odds } \\
\text { Ratio }\end{array}$} & \multicolumn{2}{|c|}{$\begin{array}{l}95 \% \text { Cl for Odds } \\
\text { Ratio }\end{array}$} \\
\hline & & & & $\mathbf{L}$ & $\mathbf{U}$ & & $\mathbf{L}$ & $\mathbf{U}$ \\
\hline Year & -0.008 & 0.002 & 0.000 & -0.012 & -0.004 & 0.99 & 0.988 & 0.996 \\
\hline $\begin{array}{l}\text { North Ash } \\
\text { Sharqiyah }\end{array}$ & 0.753 & 0.045 & 0.000 & 0.666 & 0.841 & 2.12 & 1.946 & 2.319 \\
\hline Muscat (ref) & 0.000 & - & - & - & - & 1.00 & - & - \\
\hline Ad Dakhliyah & 0.904 & 0.044 & 0.000 & 0.819 & 0.999 & 2.47 & 2.268 & 2.716 \\
\hline Al Buraymi & 0.974 & 0.043 & 0.000 & 0.889 & 1.058 & 2.65 & 2.433 & 2.881 \\
\hline Ad Dhahirah & 0.995 & 0.043 & 0.000 & 0.910 & 1.079 & 2.70 & 2.484 & 2.942 \\
\hline South Al Batinah & 1.005 & 0.043 & 0.000 & 0.921 & 1.090 & 2.73 & 2.512 & 2.974 \\
\hline North Al Batinah & 1.094 & 0.043 & 0.000 & 1.010 & 1.177 & 2.99 & 2.746 & 3.245 \\
\hline $\begin{array}{l}\text { South Ash } \\
\text { Sharqiyah }\end{array}$ & 1.447 & 0.041 & 0.000 & 1.367 & 1.527 & 4.25 & 3.923 & 4.604 \\
\hline Dhofar & 1.692 & 0.040 & 0.000 & 1.613 & 1.77 & 5.43 & 5.018 & 5.871 \\
\hline Al Wusta & 1.799 & 0.040 & 0.000 & 1.714 & 1.870 & 6.05 & 5.551 & 6.488 \\
\hline Musandam & 1.938 & 0.040 & 0.000 & 1.860 & 2.015 & 6.94 & 6.424 & 7.501 \\
\hline
\end{tabular}

\section{Discussion}

Statistics are important, whether from administrative data, surveys or controlled studies. Asthma and other chronic obstructive lung diseases are silent killers; therefore information pertaining these diseases is important to guide decision making for quality health service provision $26-28$. In this study, we have tested for region and fitted a related prediction model for ACOLD incidence rates.

The study established five ACOLD geographical regions, which are based on the incidence rates. Generally, the incidence rates remained fairly the same over the period, but started to decrease between 2016 and 2019. The lowest incidence rate was in the year 2019, possibly influenced by demographic and other socio-economic characteristics that were outside the scope of this study.

\section{Asthma incidence rates by geographical regions}

Using the analysis of variance (ANOVA) 24 we identified five groups for asthma incidence rates by regions. The grouping of eleven geographical regions into five regions was premised on incidence rates, 
their standard deviations, correlations and trends of the incidence rates over the period. There was a general consensus for the regional groups for the incidence rates.

\section{Asthma incidence using the logistic regression model}

The results from the logistic model corroborate with those obtained from the Analysis of variance. The logistic regression provided an estimate of the annual decrease by about $1 \%$ of the odds of asthma and other chronic obstructive lung disease. It also readily provides a comparison of two regions using the ratio of the two odds of asthma and other chronic obstructive lung disease for the two regions. This is obtained directly by dividing the odds of the two regions relative to Muscat by each other.

The general climate in Oman is tropical desert, almost everywhere, characterized with some summer rains in the northern and southern parts, with clouds along the eastern coast brought by the Monsoon winds. These winds, though have limited effects in terms of rain, but tend to influence the climate of the country. 29 At the coastal areas of the Gulf of Oman, the desert climate is predominant, sunny throughout the year, with some little winter rains in the far north encompassing the Musandam region. This area is extremely hot in summer, with an average high temperature of about 38 degrees Celsius, possibly due to the humidity from the sea. It has been noted that sometimes with the wind blowing from the inland, causes humidity to drop, resulting into very high temperatures of about 50 degrees Celsius. As to whether this would probably provide an explanation, why the incidence rates are the highest in the Musandam region is uncertain 30-32.

Other known clinical and gene-environmental factors associated with asthma could not be assessed in this study because of data limitation arising from the use of administrative data. However, studies show that under genetics, genome-wide linkage studies have identified 18 genome regimes and more than 100 genes associated with allergy and asthma in eleven different populations 33,34 . The prenatal risk factors may include, but not limited to prenatal tobacco smoke use, poor diet and nutrition, stress and antibiotic use 24,35 . There are also childhood risk factors that include among others, phenotypes of asthma, for example early childhood wheezing and age at onset, breastfeeding, poor lung function, family structure, low socio-economic status, exposure to environmental tobacco, exposure to animals, sex and geneenvironment interactions. However, our findings show that though, region was significant, its interaction with year was not significant 36 .

Availability of time series data for a relatively longer period would possibly provide trends and seasonality of the incidence rates among all categories of, for example; age, region and gender. Nonetheless, this study highlights the significance of distributive evidence of asthma by region.

\section{Conclusion And Policy Implications}

The fact that asthma is chronic and categorized as one of the most hazardous health threats to the economic contribution by the workforce points to the urgent need for it to be prioritized among common health risks. Its association with COVID-19 severity and poor outcome is also compelling 37 . Combatting 
this health threat primarily requires information on incidence rates; distribution and other related risk factors so as to inform decisions on human and financial resource mobilization and allocation. This study draws the conclusion that geographical region of residence has significant association with incidence rates of asthma and chronic obstructive lung diseases. As to whether, this effect may vary over time and space is yet a gap to be ascertained. The implication of our findings is that both health practitioners and policy makers should focus resources to the identified regions to abate the effect of incidence rates, since different regions have different defining characteristics, which in turn affect asthma incidences. Secondly, grouping incidence rates by region helps to focus resources and maximize reduction in the disease incidence rates because of the targeted interventions. The Ministry of Health should consider the five-asthma regions when making resources allocation decisions.

\section{Declarations}

\section{Funding}

This research did not receive funding.

\section{Conflict of interest}

The authors declare no conflict of interest.

\section{Availability of data and material}

Administrative data used are extracts from reports and are publicly available online

\section{Ethics approval}

Not applicable

\section{References}

1. Thomsen, S.F., Genetics of asthma: an introduction for the clinician. European clinical respiratory journal, 2015. 2(1): p. 24643.

2. Yang, I.V., C.A. Lozupone, and D.A. Schwartz, The environment, epigenome, and asthma. Journal of Allergy and Clinical Immunology, 2017. 140(1): p. 14-23.

3. Krautenbacher, N., et al., Asthma in farm children is more determined by genetic polymorphisms and in non-farm children by environmental factors. Pediatric Allergy and Immunology, 2021. 32(2): p. 295-304.

4. Altzibar, J., et al., Epidemiology of asthma exacerbations and their relation with environmental factors in the $B$ asque $C$ ountry. Clin Exp Allergy, 2015. 45(6): p. 1099-1108.

5. Lawson, J.A., et al., Prevalence, risk factors, and clinical outcomes of atopic and nonatopic asthma among rural children. Ann Allergy Asthma Immunol, 2017. 118(3): p. 304-310. 
6. Bayliss, H.R., et al., Evidence for changes in the occurrence, frequency or severity of human health impacts resulting from exposure to alien species in Europe: a systematic map. Environ Evid, 2017. 6(1): p. 21.

7. Burnett, R., et al., Air pollution effects on hospital admissions: a statistical analysis of parallel time series. Environmental and Ecological Statistics, 1994. 1(4): p. 325-332.

8. Holgate, S.T., The airway epithelium is central to the pathogenesis of asthma. Allergol Int, 2008. 57(1): p. 1-10.

9. Hellings, P.W. and B. Steelant, Epithelial barriers in allergy and asthma. Journal of Allergy and Clinical Immunology, 2020. 145(6): p. 1499-1509.

10. Mitchell, P.D. and P.M. O'Byrne, Epithelial-derived cytokines in asthma. Chest, 2017. 151(6): p. 13381344.

11. Buendía, E., et al., Gut microbiota components are associated with fixed airway obstruction in asthmatic patients living in the tropics. Scientific reports, 2018. 8(1): p. 1-12.

12. Tliba, O. and R.A. Panettieri Jr, Paucigranulocytic asthma: uncoupling of airway obstruction from inflammation. Journal of Allergy and Clinical Immunology, 2019. 143(4): p. 1287-1294.

13. Ma, J., et al., Pilot randomised trial of a healthy eating behavioural intervention in uncontrolled asthma. Eur Respir J 2016. 47(1): p. 122-132.

14. Bhan, N., et al., Time trends in racial and ethnic disparities in asthma prevalence in the United States from the Behavioral Risk Factor Surveillance System (BRFSS) Study (1999-2011). Am J Public Health, 2015. 105(6): p. 1269-1275.

15. Cosio, B.G., et al., Defining the asthma-COPD overlap syndrome in a COPD cohort. Chest, 2016. 149(1): p. 45-52.

16. Alves, A.M., et al., Severe asthma: Comparison of different classifications of severity and control. Respiratory medicine, 2019. 156: p. 1-7.

17. Heffler, E., et al., Inhaled corticosteroids safety and adverse effects in patients with asthma. The Journal of Allergy and Clinical Immunology: In Practice, 2018. 6(3): p. 776-781.

18. Ye, Q., X.-O. He, and A. D'Urzo, A review on the safety and efficacy of inhaled corticosteroids in the management of asthma. Pulmonary Therapy, 2017. 3(1): p. 1-18.

19. Uphoff, E., et al., A systematic review of socioeconomic position in relation to asthma and allergic diseases. Eur Respir J 2015. 46(2): p. 364-374.

20. Moradi-Lakeh, M., et al., Prevalence of asthma in Saudi adults: findings from a national household survey, 2013. BMC Pulm Med, 2015. 15(1): p. 77.

21. Al-Busaidi, N., et al., The burden of asthma in Oman. Sultan Qaboos Univ Med J, 2015. 15(2): p. e184.

22. Henson, R., Analysis of variance (ANOVA). Brain Mapping: an encyclopedic reference, 2015: p. 47781.

23. Chatfield, C., Introduction to multivariate analysis. 2018: Routledge. 
24. Andrusaityte, S., et al., Associations between neighbourhood greenness and asthma in preschool children in Kaunas, Lithuania: a case-control study. BMJ open, 2016. 6(4): p. e010341.

25. Duddek, C., et al., Multivariate imputation in cross-sectional analysis of health effects associated with air pollution. Environmental and ecological statistics, 1995. 2(3): p. 191-212.

26. D'Anna, S.E., et al., Bacterial and viral infections and related inflammatory responses in Chronic Obstructive Pulmonary Disease. Annals of Medicine, 2021. 53(1): p. 135-150.

27. Shayo, F.K. and D. Bintabara, Are Tanzanian health facilities ready to provide management of chronic respiratory diseases? An analysis of national survey for policy implications. PloS one, 2019. 14(1): p. e0210350.

28. Sharma, A.K., P. Baliyan, and P. Kumar, Air pollution and public health: the challenges for Delhi, India. Reviews on environmental health, 2018. 33(1): p. 77-86.

29. Mountjoy, M., et al., Prevalence and characteristics of asthma in the aquatic disciplines. J Allergy Clin Immunol 2015. 136(3): p. 588-594.

30. Epton, M.J., et al., Climate and aeroallergen levels in asthma: a 12 month prospective study. Thorax, 1997. 52(6): p. 528-534.

31. Beggs, P.J. and H.J. Bambrick, Is the global rise of asthma an early impact of anthropogenic climate change? Environmental health perspectives, 2005. 113(8): p. 915-919.

32. Wang, J., et al., Asthma and allergic rhinitis among young parents in China in relation to outdoor air pollution, climate and home environment. Science of the Total Environment, 2021. 751: p. 141734.

33. Shrine, N., et al., Moderate-to-severe asthma in individuals of European ancestry: a genome-wide association study. The Lancet Respiratory Medicine, 2019. 7(1): p. 20-34.

34. Miller, G.E., et al., Divergent transcriptional profiles in pediatric asthma patients of low and high socioeconomic status. Pediatric pulmonology, 2018. 53(6): p. 710-719.

35. Vlaski, E. and J. Lawson, Urban-rural differences in asthma prevalence among young adolescents: The role of behavioural and environmental factors. Allergol Immunopathol, 2015. 43(2): p. 131-141.

36. Akinbami, L.J., A.E. Simon, and L.M. Rossen, Changing trends in asthma prevalence among children. Pediatrics, 2016. 137(1): p. e20152354.

37. Eger, K., et al., Poor outcome of SARS-CoV-2 infection in patients with severe asthma on biologic therapy. Respiratory Medicine, 2021. 177: p. 106287.

\section{Figures}




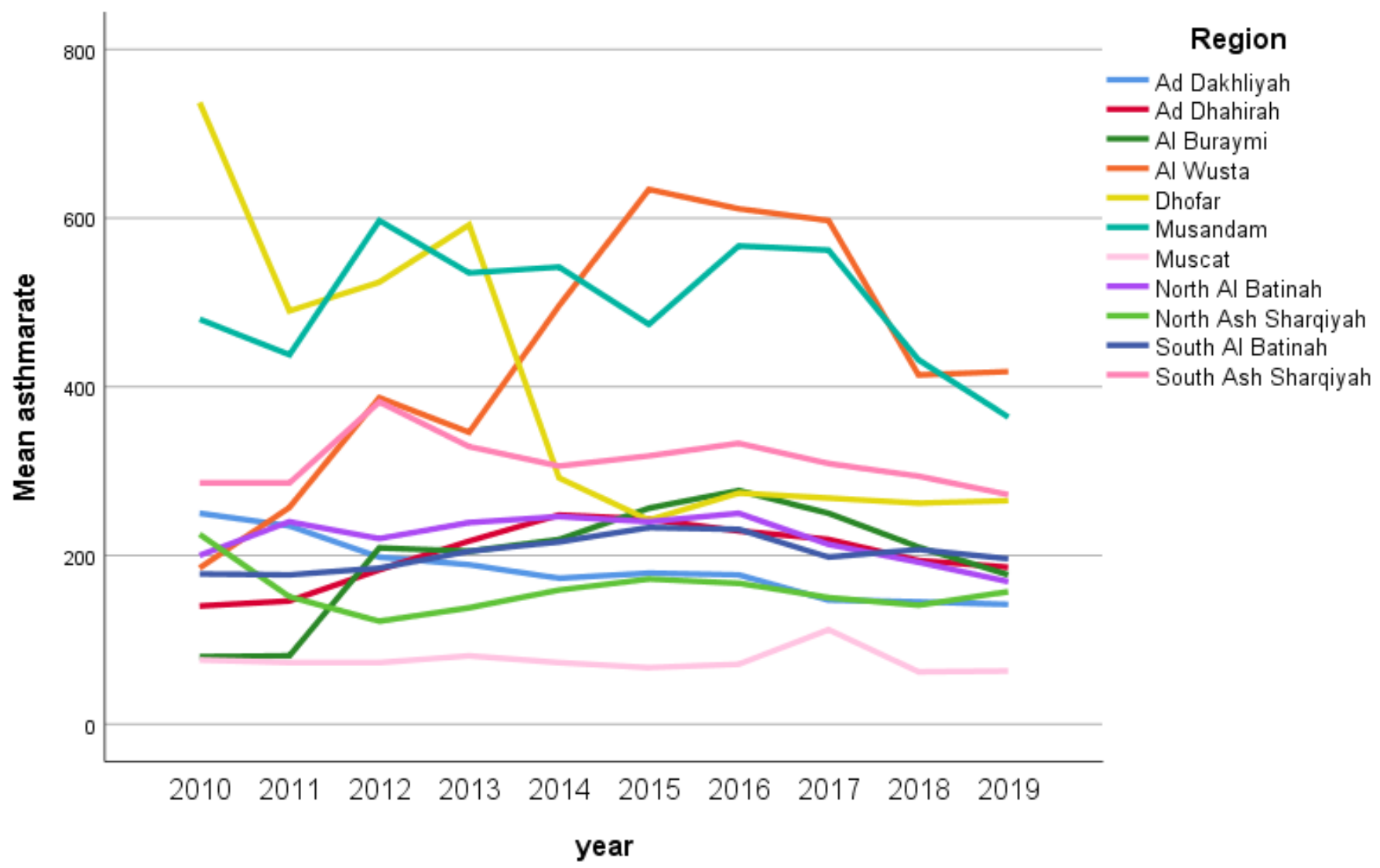

Figure 1

Incidence rates of Asthma over the eleven regions by year (2010-2019). 